\title{
Association of Patients' Perception of Primary Care Provider Listening With Emergency Department Use
}

\author{
Katie Hinderaker, MD | Amanda Weinmann, MD, MS
}

PRiMER. 2020;4:7.

Published: 5/22/2020 | DOI: 10.22454/PRiMER.2020.951748

\section{Abstract}

Introduction: This study examined whether patients' perceptions of their primary care providers' (PCP) listening frequency were associated with emergency department (ED) utilization, including a comparison to patients without PCPs.

Methods: Data were obtained from the 2015 California Health Interview Survey. Respondents were asked if they had a PCP and how often their PCPs listened, resulting in five groups: patients without a PCP $(n=4,407)$, and patients with a PCP who perceived the PCP's listening frequency to be never $(n=254)$, sometimes $(n=1,282)$, usually $(n=3,440)$, or always $(n=11,651)$. Multiple linear regression was performed to determine if patient-perceived listening frequency of the PCP was associated with the patient's number of ED visits in the prior year, adjusting for various demographic, social, and health factors.

Results: Compared to patients without a PCP, patients with a PCP had on average 0.15 more ED visits in a year, highest among those whose PCPs were perceived as listening the least: never $=0.55$ more visits per year $(95 \%$ $\mathrm{Cl}: 0.09-1.02, P=.02)$, sometimes $=0.26(0.01-0.51, P=.04)$, usually $=0.03(-0.17-0.24, P=.73)$, and always $=0.16$ $(-0.05-0.36, P=.13)$. Other significant increases in ED visits were associated with public insurance, AfricanAmerican race, English proficiency, younger age, self-rated fair-to-poor health, asthma, and hypertension.

Conclusions: Patients who perceived their PCP as listening less frequently had more ED visits than patients whose PCPs were perceived as listening more frequently, and compared to patients without a PCP.

\section{Introduction}

There are over 140 million visits annually to emergency departments (ED) in the United States. ${ }^{1}$ An estimated $13 \%-27 \%$ are considered preventable, costing $\$ 4.4$ billion annually. ${ }^{2}$ Research is mixed on whether having a primary care provider (PCP) is associated with increased or decreased ED utilization, ${ }^{3-8}$ with prior studies showing confounding variables regarding demographics, health, and socioeconomic status. ${ }^{3-5,8}$

Listening is crucial to the provider-patient relationship. ${ }^{9-12}$ We hypothesized that patients' perceptions of provider listening may contribute to the disparate results of previous studies regarding PCP status and ED utilization. To our knowledge, no prior studies have assessed perceived listening and ED utilization. This study examined if ED utilization is associated with patients' perceptions of how often their PCPs listen, including a comparison to patients without a PCP. 


\section{Methods}

We obtained data from the online 2015 California Health Interview Survey (CHIS) ${ }^{13}$ and its associated public use data files. CHIS is a large, telephone-based, cross-sectional survey of Californians about various health topics with data freely-accessible online for public analysis. The information was publicly available and subjects were unidentified, therefore institutional review board approval was not required. CHIS screeners obtained informed consent prior to proceeding with interviews.

The survey asked adult participants the question "Do you have a personal doctor or medical provider who is your main provider?" Perceptions of PCP listening frequency were determined by the question: "How often does your doctor or medical provider listen carefully to you?" Responses included "never," "sometimes," "usually," or "always." The survey asked participants how many times they had used the ED in the past 12 months, ranging from 0 to 5 or more than 5 times. Potential confounding variables were predefined based on previous studies. ${ }^{1,7,14-16}$ These included age, gender, race/ethnicity, English proficiency, insurance status, income, education, general health status, and health conditions, including asthma, diabetes, heart failure, and hypertension.

We performed statistical analysis using SAS Studio 3.71. ${ }^{17}$ Baseline characteristics were compared using one-way analysis of variance and $\chi^{2}$ test for continuous and categorical/ordinal variables, respectively. We performed a multiple linear regression using a zero-inflated Poisson distribution was performed to determine if the patientperceived listening frequency of the PCP was associated with the number of ED visits in the prior year, adjusting for the predefined demographic, socioeconomic, and health factors mentioned.

\section{Results}

There were 21,034 respondents divided between five groups: those without a PCP, and, among those with a PCP, four groups of patient-perceived listening frequency of their PCPs. There were significant differences between the groups' baseline characteristics (Table 1).

Adjusting for demographics, (age, sex, and race), social factors (education, income, English proficiency, and insurance status), and health factors (general health rating, asthma, heart failure, hypertension, and diabetes), respondents with a PCP had on average 0.15 more ED visits in a year. The highest rate of ED visits was among patients whose PCPs were perceived as listening the least: never $=0.55$ more visits per year $(95 \% \mathrm{Cl}: 0.09-1.02$, $P=.02)$, sometimes $=0.26(0.01-0.51, P=.04)$, usually=0.03 (-0.17- $0.24, P=.73)$, and always $=0.16(-0.05-0.36, P=.13$; Table 2). These results were only significantly different from the non-PCP group at the lower levels of perceived listening. Other significant increases in ED visits were associated with public insurance, African-American race, English proficiency, younger age, self-rated fair-to-poor health, asthma, and hypertension (Table 2).

\section{Conclusions}

The purpose of this study was to assess whether the frequency that a patient perceives their primary care provider to listen is associated with ED utilization in the prior year, adjusting for demographics, social factors, and health factors. There were two major conclusions: (1) compared to patients without a PCP, those with a PCP tended to have more ED visits, and (2) there were more ED visits associated with PCPs perceived to listen less, though this was only significant at the lower listening frequencies (never and sometimes).

This study found younger age, African-American race, English proficiency, public insurance, poor-to-fair general health status, asthma, and hypertension were associated with an increased number of ED visits in the prior year. The effects of income, diabetes, heart failure, and education were not statistically significant. This somewhat correlates with other studies suggesting chronic disease leads to increased ED utilization, ${ }^{7,8}$ however certain chronic diseases were statistically significant while others were not. The diseases included all tended toward increased ED visits.

Hypertension had a greater prevalence, thus making it more likely for the results to be significant. As asthma can be highly symptomatic with rapid onset of exacerbations, this may lead patients to be more likely to seek care 
emergently. We postulate patients with limited English proficiency may be less likely to access the health care system due to language barriers. In some studies, younger patients were found to be more likely to use the ED. 7,18 However, other studies described both older and younger patients being more likely to use the ED than middle-aged patients, ${ }^{19}$ so there may be a bimodal effect that is not well characterized by the linear regression analysis of this study.

The strengths of the study include the large, diverse sample and a multiple linear regression controlling for many confounding variables. Unlike past studies, this study investigated ED utilization relating to a component of the qualitative nature of the patient-PCP relationship. Limitations of this study include unknown generalizability beyond California and potential reporting bias from the telephone survey. Listening is only one facet of patient-PCP relationships and may not reflect the entire quality of the relationship. There may be additional components of the patient-PCP relationship contributing to ED utilization that were not assessed in this study. Provider listening as reported by patients is subject to multiple biases and may not reflect if the provider was actually listening. However, providers often overestimate their own listening skills, ${ }^{20}$ so these findings may more closely align with the patients' perspectives. This study was limited by the survey capping ED visits' maximum at " 5 or more," so coefficient results may be underestimated.

This study provides insight into factors relating to increased ED utilization from a large diverse sample, and suggests that having a PCP perceived as being a less frequent listener is associated with increased ED use. We hope this study inspires PCPs to consider how their patients perceive their listening, and consider strategies to improve their listening skills. ${ }^{21,22}$

\section{Tables and Figures}


Table 1: Characteristics of Survey Respondents, Reported by Patient-

Perceived Listening Frequency of Primary Care Provider

\begin{tabular}{|c|c|c|c|c|c|c|}
\hline \multirow{2}{*}{ Characteristic } & \multirow{2}{*}{ No PCP } & \multicolumn{4}{|c|}{ Patient-Perceived Listening Frequency of PCP } & \multirow{2}{*}{$P$ Value } \\
\hline & & Never & Sometimes & Usually & Always & \\
\hline Number & 4,407 & 254 & 1,282 & 3,440 & 11,651 & \\
\hline ED visits in past year & $0.33 \pm 0.86$ & $0.75 \pm 1.3$ & $0.58 \pm 1.1$ & $0.37 \pm 0.89$ & $0.41 \pm 0.94$ & $<.001$ \\
\hline Age in years & $41 \pm 18$ & $49 \pm 18$ & $53 \pm 18$ & $55 \pm 18$ & $58 \pm 17$ & $<.001$ \\
\hline Income (thousands of dollars) & $50 \pm 56$ & $51 \pm 51$ & $60 \pm 60$ & $80 \pm 69$ & $78 \pm 69$ & $<.001$ \\
\hline Gender, n (\%) & & & & & & $<.001$ \\
\hline Female & $2,024(46)$ & $144(57)$ & $806(63)$ & $2,194(64)$ & $6,837(59)$ & \\
\hline Male & $2,383(54)$ & $110(43)$ & $476(37)$ & $1,246(36)$ & $4,814(41)$ & \\
\hline Race/Ethnicity, n (\%) & & & & & & $<.001$ \\
\hline White & $1,704(39)$ & $119(47)$ & $715(56)$ & $2,282(66)$ & $7,661(66)$ & \\
\hline Hispanic & $1,928(44)$ & $85(33)$ & $301(23)$ & $605(18)$ & $2,040(18)$ & \\
\hline Asian & $376(9)$ & $22(9)$ & $107(8)$ & $304(9)$ & $762(7)$ & \\
\hline African American & $226(5)$ & $13(5)$ & $94(7)$ & $142(4)$ & $744(6)$ & \\
\hline American Indian & $41(1)$ & $3(1)$ & $16(1)$ & $24(1)$ & $118(1)$ & \\
\hline Multiracial or other & $132(3)$ & $12(5)$ & $49(4)$ & $83(2)$ & $326(3)$ & \\
\hline English Proficiency, n (\%) & & & & & & $<.001$ \\
\hline Proficient & $3,404(77)$ & $216(85)$ & $1,146(89)$ & $3,175(92)$ & $10,927(94)$ & \\
\hline Limited or none & $1,003(23)$ & $38(15)$ & $136(11)$ & $265(8)$ & $724(6)$ & \\
\hline Insurance Status, n (\%) & & & & & & $<.001$ \\
\hline Public & $1,923(44)$ & $164(65)$ & $732(57)$ & $1,753(51)$ & $6,828(59)$ & \\
\hline Private & $1,447(33)$ & $77(30)$ & $503(39)$ & $1,595(46)$ & $4,539(39)$ & \\
\hline None & $1,037(24)$ & $13(5)$ & $47(4)$ & $92(3)$ & $284(2)$ & \\
\hline Education, n (\%) & & & & & & $<.001$ \\
\hline High school or less & $2,289(52)$ & $121(48)$ & $454(35)$ & $869(25)$ & $3,362(29)$ & \\
\hline Some college or more & $2,118(48)$ & $133(52)$ & $828(65)$ & $2,571(75)$ & $8,289(71)$ & \\
\hline Self-rated General Health, n (\%) & & & & & & $<.001$ \\
\hline Excellent or good & $3,421(78)$ & $169(67)$ & $845(66)$ & $2,689(78)$ & $9,137(78)$ & \\
\hline Fair or poor & $986(22)$ & $85(33)$ & $437(34)$ & $751(22)$ & $2,514(22)$ & \\
\hline Asthma, n (\%) & & & & & & $<.001$ \\
\hline No & $4,130(94)$ & $220(87)$ & $1,115(87)$ & $3,072(89)$ & $10,427(89)$ & \\
\hline Yes & $277(6)$ & $34(13)$ & $167(13)$ & $368(11)$ & $1,224(11)$ & \\
\hline Diabetes, n (\%) & & & & & & $<.001$ \\
\hline No & $4,119(93)$ & $218(86)$ & $1,096(85)$ & $3,062(89)$ & $9,983(86)$ & \\
\hline Yes & $288(7)$ & $36(14)$ & $186(15)$ & $378(11)$ & $1,668(14)$ & \\
\hline Heart Failure, n (\%) & & & & & & $<.001$ \\
\hline No & $4,344(99)$ & $248(98)$ & $1,238(97)$ & $3,341(97)$ & $11,135(96)$ & \\
\hline Yes & $63(1)$ & $6(2)$ & $44(3)$ & $99(3)$ & $516(4)$ & \\
\hline High Blood Pressure, n (\%) & & & & & & $<.001$ \\
\hline No & $3,480(79)$ & $168(66)$ & $730(57)$ & $2,145(62)$ & $6,568(56)$ & \\
\hline Yes & $927(21)$ & $86(34)$ & $552(43)$ & $1,295(38)$ & $5,083(44)$ & \\
\hline
\end{tabular}

Abbreviation: PCP, primary care provider.

Values presented as number (percentage within-group), or mean $\pm \mathrm{SD}$. 
Table 2: Results of Multiple Linear Regression Model of Predictors of ED Visits in Past Year

\begin{tabular}{|c|c|c|c|}
\hline Characteristic & $\mathrm{n}(\%)$ & Coefficient ( $95 \%$ Cl) & $P$ Value \\
\hline \multicolumn{4}{|c|}{ Patient-Perceived PCP Listening Frequency } \\
\hline No PCP & $4,407(21)$ & Reference & \\
\hline Never listens & $254(1)$ & 0.55 (0.09 to 1.02$)$ & .02 \\
\hline Sometimes listens & $1,282(6)$ & $0.26(0.01$ to 0.51$)$ & .04 \\
\hline Usually listens & $3,440(16)$ & $0.03(-0.17$ to 0.24$)$ & .73 \\
\hline Always listens & $11,651(55)$ & $0.16(-0.05$ to 0.36$)$ & .13 \\
\hline \multicolumn{4}{|l|}{ Gender } \\
\hline Female & $12,005(57)$ & Reference & \\
\hline Male & $9,029(43)$ & $0.05(-0.07$ to 0.17$)$ & .39 \\
\hline Age (per 5-year Increment) & $53 \pm 18$ & $-0.05(-0.07$ to -0.03$)$ & $<.001$ \\
\hline \multicolumn{4}{|l|}{ Race/Ethnicity } \\
\hline White & $12,481(59)$ & Reference & \\
\hline Hispanic & $4,959(24)$ & $0.03(-0.13$ to 0.20$)$ & .70 \\
\hline Asian & $1,571(7)$ & $-0.19(-0.47$ to 0.09$)$ & .18 \\
\hline African American & $1,219(6)$ & $0.30(0.11$ to 0.49$)$ & .003 \\
\hline American Indian & $202(1)$ & $0.26(-0.12$ to 0.64$)$ & .18 \\
\hline Multiracial or other & $602(3)$ & $0.25(-0.11$ to 0.61$)$ & .18 \\
\hline \multicolumn{4}{|l|}{ English Proficiency } \\
\hline Proficient & $18,868(90)$ & Reference & \\
\hline Limited or none & $2,166(10)$ & $-0.44(-0.68$ to -0.19$)$ & $<.001$ \\
\hline \multicolumn{4}{|l|}{ Insurance status } \\
\hline Public & $11,400(54)$ & Reference & \\
\hline Private & $8,161(39)$ & $-0.37(-0.57$ to -0.17$)$ & $<.001$ \\
\hline None & $1,473(7)$ & $-0.41(-0.71$ to -0.12$)$ & .006 \\
\hline Income (Thousands of Dollars) & $71 \pm 67$ & $0.00(0.00$ to 0.00$)$ & .07 \\
\hline \multicolumn{4}{|l|}{ Education } \\
\hline High school or less & $7,095(34)$ & Reference & \\
\hline Some college or more & $13,939(66)$ & $0.08(-0.06$ to 0.22$)$ & .26 \\
\hline \multicolumn{4}{|l|}{ Self-rated General Health } \\
\hline Excellent or good & $16,261(77)$ & Reference & \\
\hline Fair or poor & $4,773(23)$ & $0.52(0.35$ to 0.69$)$ & $<.001$ \\
\hline \multicolumn{4}{|l|}{ Asthma } \\
\hline No & $18,964(90)$ & Reference & \\
\hline Yes & $2,070(10)$ & $0.22(0.06$ to 0.39$)$ & .007 \\
\hline \multicolumn{4}{|l|}{ Diabetes } \\
\hline No & $18,478(88)$ & Reference & \\
\hline Yes & $2,556(12)$ & $0.01(-0.23$ to 0.25$)$ & .96 \\
\hline \multicolumn{4}{|l|}{ Heart failure } \\
\hline No & $20,306(97)$ & Reference & \\
\hline Yes & $728(3)$ & $0.20(-0.07$ to 0.47$)$ & .14 \\
\hline \multicolumn{4}{|l|}{ High Blood Pressure } \\
\hline No & $13,091(62)$ & Reference & \\
\hline Yes & $7943(38)$ & $0.15(0.01$ to 0.29$)$ & .04 \\
\hline
\end{tabular}

Abbreviation: $\mathrm{PCP}$, primary care provider. 


\section{Acknowledgments}

Presentations: This study was presented as a poster exhibit at the Minnesota Academy of Family Physicians: Research and Innovation Forum in Bloomington, Minnesota, March 3, 2018. It was also presented at the American Academy of Family Physicians National Conference of Family Medicine Residents and Students in Kansas City, Missouri, August 3, 2018.

\section{Corresponding Author}

Amanda Weinmann, MD, MS

University of Minnesota Physicians - Bethesda Clinic, 580 Rice Street, St. Paul, MN 55103. 651-223-7348. Fax: 651-227-1804

wein0153@umn.edu

\section{Author Affiliations}

Katie Hinderaker, MD - University of Minnesota Department of Family Medicine and Community Health, Minneapolis, $\mathrm{MN}$

Amanda Weinmann, MD, MS - University of Minnesota Department of Family Medicine and Community Health, Minneapolis, MN

\section{References}

1. National Center for Health Statistics. National Hospital Ambulatory Medical Care Survey: 2014 Emergency Department Summary Tables. https://www.cdc.gov/nchs/data/nhamcs/web_tables /2014_ed_web_tables.pdf. Accessed February 21, 2018.

2. Weinick RM, Burns RM, Mehrotra A. Many emergency department visits could be managed at urgent care centers and retail clinics. Health Aff (Millwood). 2010;29(9):1630-1636. https://doi.org/10.1377 /hlthaff.2009.0748

3. Liaw W, Petterson S, Rabin DL, Bazemore A. The impact of insurance and a usual source of care on emergency department use in the United States. Int J Family Med. 2014;1-5. https://doi.org/10.1155 /2014/842847

4. McCusker J, Roberge $D$, Lévesque J-F, et al. Emergency department visits and primary care among adults with chronic conditions. Med Care. 2010;48(11):972-980. https://doi.org/10.1097/MLR.0b013e3181eaf86d

5. Mian O, Pong R. Does better access to FPs decrease the likelihood of emergency department use? Results from the Primary Care Access Survey. Can Fam Physician. 2012;58(11):e658-e666.

6. Rosenblatt RA, Wright GE, Baldwin L-M, et al. The effect of the doctor-patient relationship on emergency department use among the elderly. Am J Public Health. 2000;90(1):97-102. https://doi.org/10.2105 /AJPH.90.1.97

7. Maeng DD, Hao J, Bulger JB. Patterns of Multiple Emergency Department Visits: Do Primary Care Physicians Matter? Perm J. 2017;21:16-063. https://doi.org/10.7812/TPP/16-063

8. Vinton DT, Capp R, Rooks SP, Abbott JT, Ginde AA, Ginde AA. Frequent users of US emergency departments: characteristics and opportunities for intervention. Emerg Med J. 2014;31(7):526-532. https://doi.org/10.1136 /emermed-2013-202407

9. Razzaghi MR, Afshar L. A conceptual model of physician-patient relationships: a qualitative study. J Med Ethics Hist Med. 2016;9:14.

10. Paternotte E, van Dulmen S, Bank L, Seeleman C, Scherpbier A, Scheele F. Intercultural communication through the eyes of patients: experiences and preferences. Int J Med Educ. 2017;8:170-175. https://doi.org /10.5116/ijme.591b.19f9

11. Percival J, Donovan J, Kessler D, Turner K. 'She believed in me'. What patients with depression value in their relationship with practitioners. A secondary analysis of multiple qualitative data sets. Health Expect. 2017;20(1):85-97. https://doi.org/10.1111/hex.12436 
12. Jagosh J, Donald Boudreau J, Steinert Y, Macdonald ME, Ingram L. The importance of physician listening from the patients' perspective: enhancing diagnosis, healing, and the doctor-patient relationship. Patient Educ Couns. 2011;85(3):369-374. https://doi.org/10.1016/j.pec.2011.01.028

13. California Health Interview Survey. CHIS 2015 Adult Public Use File. Los Angeles, CA: UCLA Center for Health Policy Research; August 2017.

14. LaCalle E, Rabin E. Frequent users of emergency departments: the myths, the data, and the policy implications. Ann Emerg Med. 2010;56(1):42-48. https://doi.org/10.1016/j.annemergmed.2010.01.032

15. Villani J, Mortensen K. Nonemergent emergency department use among patients with a usual source of care. J Am Board Fam Med. 2013;26(6):680-691. https://doi.org/10.3122/jabfm.2013.06.120327

16. Weisz D, Gusmano MK, Wong G, Trombley J. Emergency department use: a reflection of poor primary care access? Am J Manag Care. 2015;21(2):e152-e160.

17. SAS Institute. Getting Started with Programming in SAS Studio 3.71 SAS Documentation. Cary, NC: SAS Institute, Inc; 2017. https://documentation.sas.com/api/docsets/webeditorgs/3.71/content /webeditorgs.pdf?locale=en. Accessed August 7, 2019.

18. Cowling TE, Cecil EV, Soljak MA, et al. Access to primary care and visits to emergency departments in England: a cross-sectional, population-based study. PLoS One. 2013;8(6):e66699. https://doi.org/10.1371 /journal.pone.0066699

19. Janke AT, Brody AM, Overbeek DL, Bedford JC, Welch RD, Levy PD. Access to care issues and the role of EDs in the wake of the Affordable Care Act. Am J Emerg Med. 2015;33(2):181-185. https://doi.org/10.1016 /j.ajem.2014.11.006

20. Ha JF, Longnecker N. Doctor-patient communication: a review. Ochsner J. 2010;10(1):38-43.

21. Buffington A, Wenner P, Brandenburg D, Berge J, Sherman M, Danner C. The Art of Listening. Minn Med. 2016;99(6):46-48.

Copyright $₫ 2020$ by the Society of Teachers of Family Medicine 